\title{
WHAT INTERNATIONAL DONORS SHOULD Know About Drought and Conflict in SUB-SAHARAN AFRICA
}

\author{
an OEF Research Policy BRIEF \\ by Curtis Bell
}

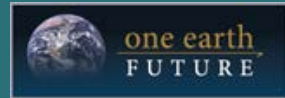

R E S E A R C H

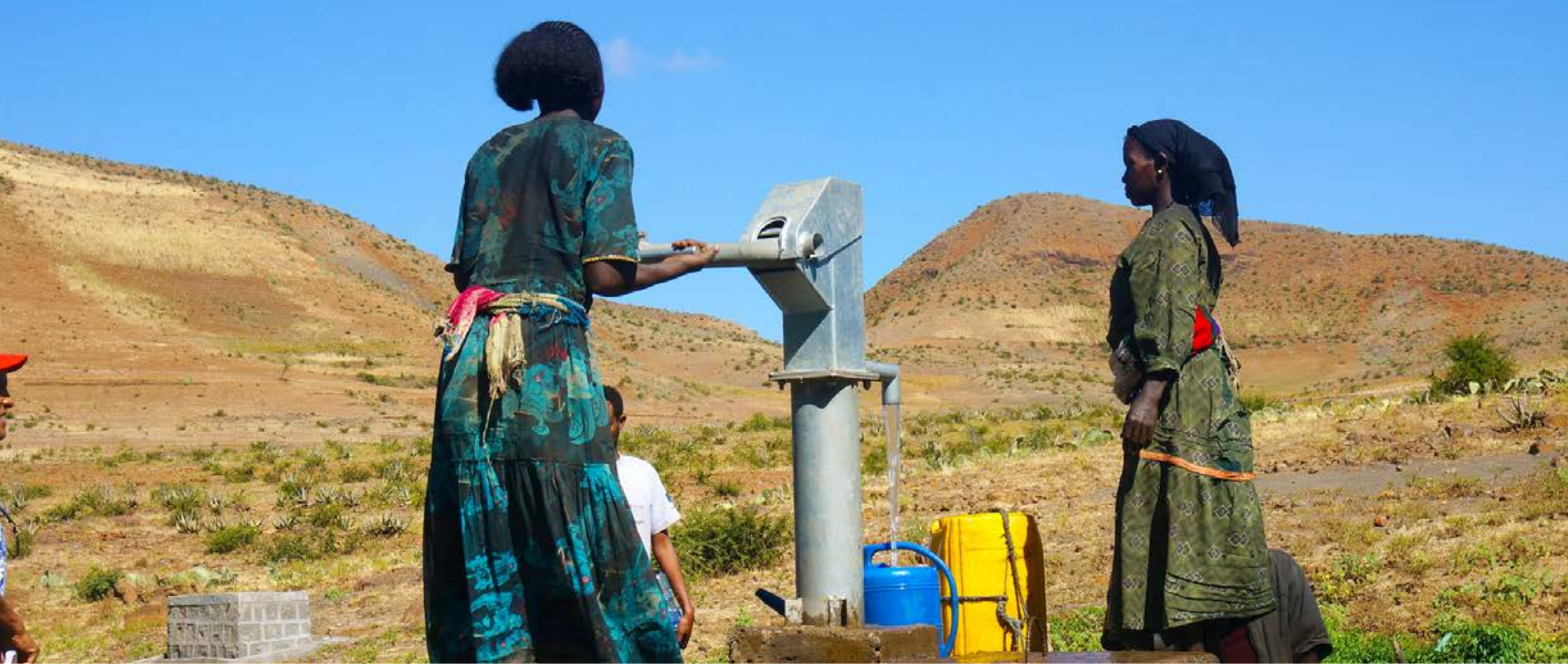

Some argue that climate change effects pose one of the greatest risks for political violence, and others argue there is no relationship whatsoever. A new study shows that there is a gray area between these two sides. Conflict brought on by scarcity of resources does occur, under very specific conditions. The following policy implications arise from this study, which is explained in more detail in this brief.

\section{Policy Implications:}

- Requests for international climate adaptation aid outpace international donors' organizational and financial capacities to meet these needs. Donors must prioritize adaptation projects and be sensitive to the relative risks of political violence induced by extreme weather events.

> If donors hope to prioritize adaptation assistance for the countries that are most likely to suffer destabilizing political violence, then they cannot simply assume the least-developed states should be given the highest priority. In sub-Saharan Africa, severe drought has historically been more likely to precede violent civil conflict in middle-income countries than in the poorest states.

International donors must be cognizant of local and traditional adaptation strategies, such as norms of resource sharing during crisis, weather-induced migration, agricultural adaptation, and even pastoralism. Often, such practices reduce conflict risks during severe weather-even in extraordinarily poor states. 


\section{WHAT INTERNATIONAL DONORS SHOULD KNOW ABOUT DROUGHT AND CONFLICT IN SUB-SAHARAN AFRICA}

\section{RESEARCH SUMMARY}

Climatologists overwhelmingly agree that greenhouse gas emissions are causing rapid climate change on a global scale. They also agree that the consequences of climate change will be more severe in some regions than in others. In particular, the areas facing the greatest risk of weather extremes tend to have the weakest economies, the greatest dependence on agriculture, and the most fragile governments.

However, there is far less agreement about the likely political consequences of climate change. Much of the public discourse focuses on water wars and violent conflicts over increasingly scarce resources. Obama administration officials

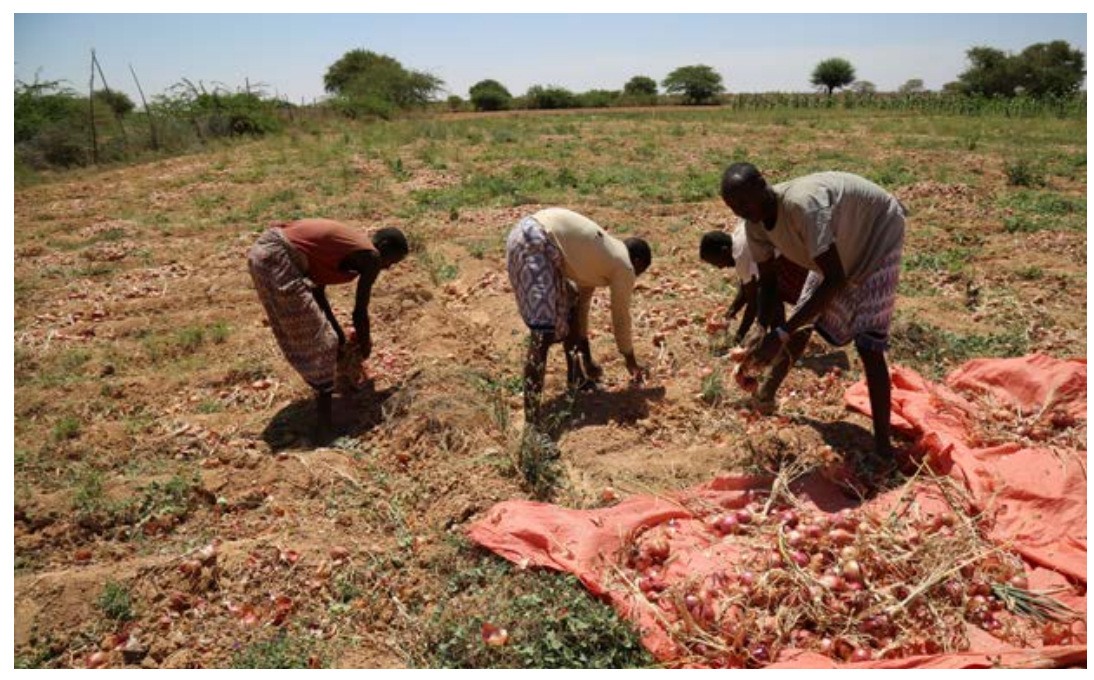

Onion farmers in Puntland, Somalia. Photo by Jean-Pierre Larroque.

research finds scant evidence for this grim, sensational climate-conflict argument. Instead, rigorous research on climate change and conflict generally concludes there is no link whatsoever between the onset of severe weather and an increase in various forms of political violence.

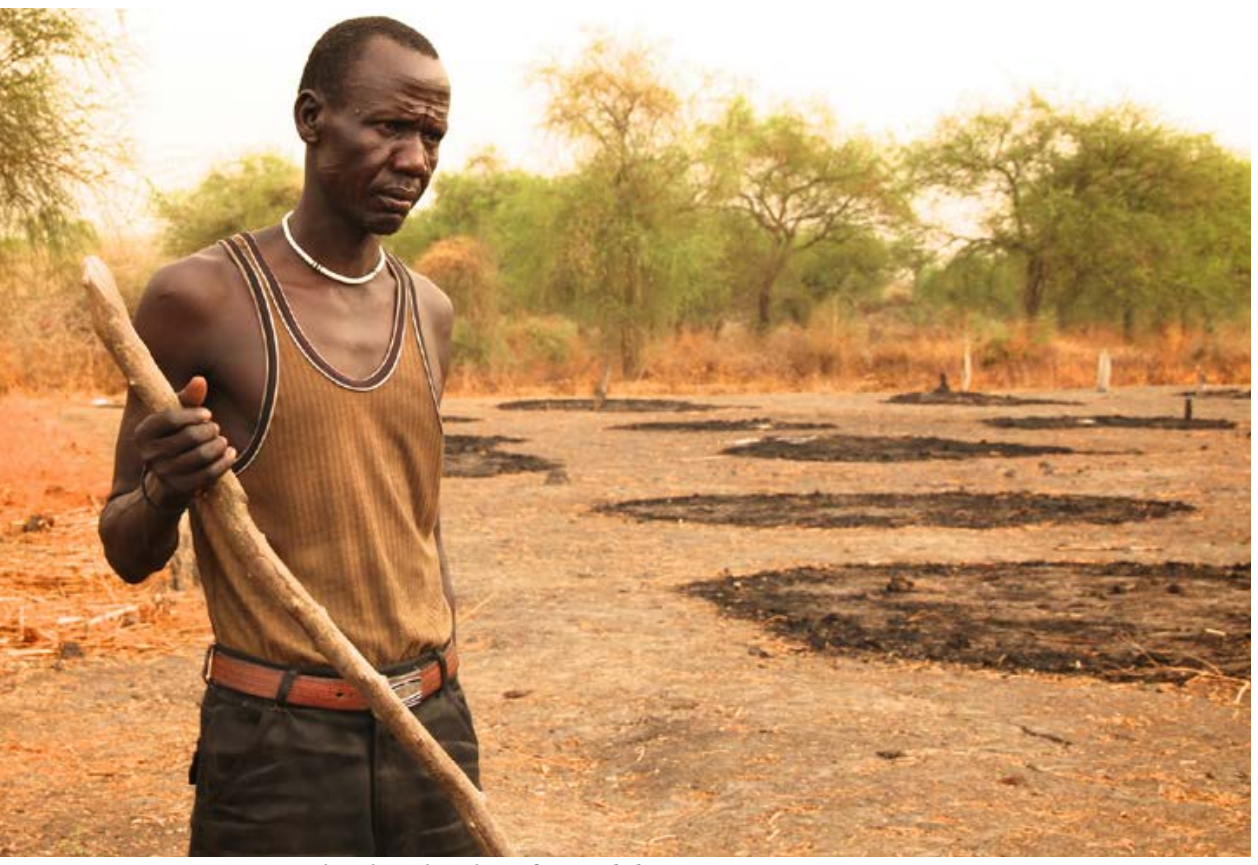

Farmer in South Sudan. Photo by Oxfam on Flickr.
A new study published by Dr. Curtis Bell of One Earth Future and Dr. Patrick W. Keys of Keys Consulting, Inc. suggests the relationship between weather extremes and political violence is complex enough that both sides of this debate can be correct. In the context of sub-Saharan Africa, drought does not generally lead to an increased risk of violent civil conflict. However, scarcity-induced conflict occurs under very specific conditions. In other words, severe drought is indeed the "mother of all risks" in some countries, but it is also irrelevant to conflict risks in others. Knowing where drought is most likely to cause conflict can help the international community more effectively prioritize climate adaptation projects. The paper is published in the peer-reviewed journal Foreign Policy Analysis.

Bell and Keys anticipated that the link between severe drought and violent civil conflict would be strongest under three conditions:

1 Social vulnerability: Where populations face greater economic and physical insecurity, the additional stressors brought by severe weather should increase conflict risks.

2 Weak state capacity: Fragile states without established and transparent political institutions should be less capable of addressing weather-related crises, and this could increase frustration with the state and fuel violent conflict.

3 Unequal distribution of resources: Fractionalized societies where one group benefits at the expense of others should be especially prone to scarcity-induced violence as increased group competition over resources amplifies social hostility or perceptions of government favoritism. 
These arguments are supported by high-profile cases of scarcity-induced conflicts like the recent wars in Darfur and Yemen. Bell and Keys were surprised to find that these are anomalies. In fact, countries with these qualities are not destabilized by severe drought nearly as much as countries with higher standards of living.

How can we explain the finding that middle-income countries with greater equality between ethnic groups, better food security, and more effective political systems are most likely to be destabilized by adverse weather? Existing research provides two plausible explanations:

First, behavioral economists have long argued that one's absolute condition is less relevant than how one views their present condition relative to a reference point in the past. This "endowment effect" argument would predict that people who are accustomed to scarcity will be less prone to violence when confronted with marginally worse living conditions than people who are accustomed to having plenty. Those living under weak and ineffective governments never expect political solutions to their problems and are therefore less resentful during disasters. Citizens who have come to expect effective government responses will be more resentful when their government fails during a crisis.

Second, local institutions-both formal and informal-can fill the void left by ineffective governments. Field work in very weak states reveals clan-level and village-level resource sharing agreements that insulate people from the effects of prolonged scarcity. People in these societies are also more likely to adapt through means like pastoralism and migration. These local responses to scarcity are not needed where people are dependent upon capable states. This causes these states to suffer more organized political violence when they fail to provide assistance during drought-induced periods of scarcity.

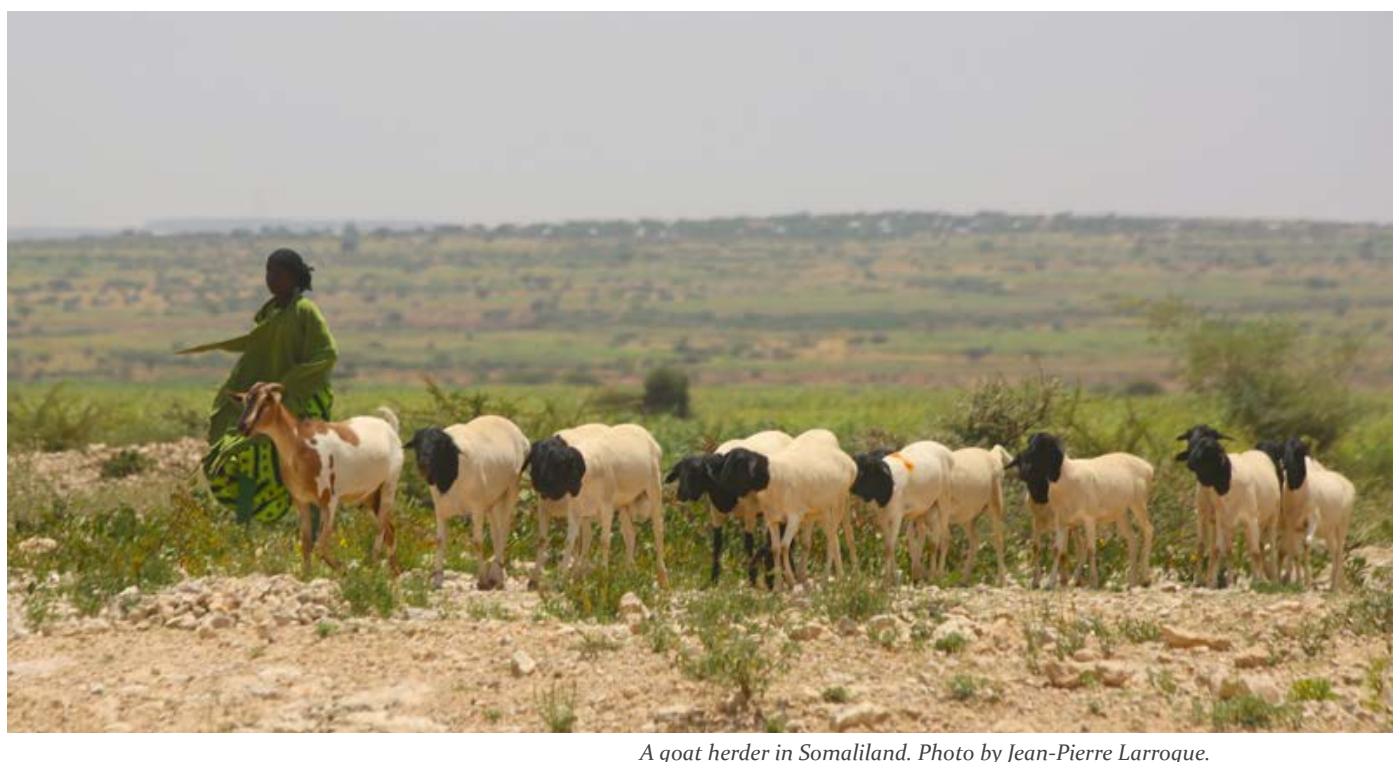

These findings show that it is not safe to assume that the poorest or most unequal states are the least prepared to confront global climate change. The relationship between scarcity and conflict is complex and our understanding of climate-related conflict must account for local norms for resource-sharing and the psychological effects of having once had plenty. By doing so, international donors can more effectively allocate adaptation aid in a way that will minimize the chances of future wars over resources threatened by our changing climate. 


\section{BACKGROUND}

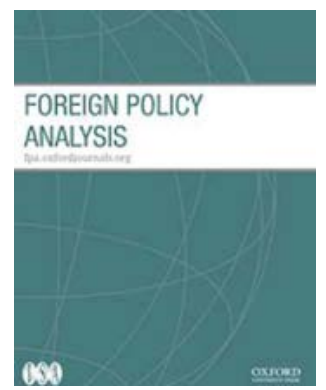

There is much debate on whether conflict-induced resource scarcity causes conflict, but there are few cross-national studies on the relationship between the two. Authors Curtis Bell of OEF Research and Patrick W. Keys of Keys Consulting, Inc. analyzed drought severity and civil conflict in sub-Saharan Africa from 1962 to 2006. The study was published in Foreign Policy Analysis in August 2016.

DOI: 10.1093/fpa/orw002

\section{8? one earth F U T U R E}

R E S E A R C H
OEF Research, a program of the One Earth Future Foundation, believes that policy and practice reflect the quality of available information. We promote empirically-informed research developed using methodologically rigorous approaches as a tool for policy making in peace, security, and good governance. It believes in analyzing evidence using both quantitative and qualitative best practices. We also believe the most innovative solutions to problems of conflict and peace necessarily involve a diverse set of disciplinary and sectoral viewpoints. Much of our work aims to break down the barriers between these different perspectives.

For more information, visit oefresearch.org 